\title{
A Grinnellian Niche Perspective on Species-Area Relationships
}

\author{
Jorge Soberón* \\ Biodiversity Institute and Department of Ecology and Evolutionary Biology, University of Kansas, Lawrence, Kansas 66045 \\ Submitted August 22, 2018; Accepted June 5, 2019; Electronically published October 23, 2019 \\ Online enhancements: appendix. Dryad data: https://doi.org/10.5061/dryad.84bq56t.
}

\begin{abstract}
A вStract: In this work, Grinnellian niche theory (a body of theory about geographic distributions of species in terms of noninteracting niche variables) is used to demonstrate that species-area relationships emerge with both size of environmental space and size of geographic area. As environmental space increases, more species' fundamental niches are included, thus increasing the number of species capable of living in the corresponding region. This idea is made operational by proposing a size measure for multidimensional environmental space and approximating fundamental niches with minimum volume ellipsoids. This framework allows estimating a presence-absence matrix based on the distribution of fundamental niches in environmental space, from which many biodiversity measures can be calculated, such as beta diversity. I establish that Whittaker's equation for beta diversity is equivalent to MacArthur's formula relating species numbers and niche breadth; this latter equation provides a mechanism for the species-niche space relationship. I illustrate the theoretical results via exploration of niches of the terrestrial mammals of North America (north of Panama). Each world region has a unique structure of its environmental space, and the position of fundamental niches in niche space is different for different clades; therefore, species-area relationships depend on the clades involved and the region of focus, mostly as a function of MacArthur's niche beta diversity. Analyzing speciesarea relationships from the perspective of niche position in environmental space is novel, shifting emphasis from demographic processes to historical, geographic, and climatic factors; moreover, the Grinnellian approach is based on available data and is computationally feasible.
\end{abstract}

Keywords: species-area relationships, fundamental niche, niche space, presence-absence matrices, beta diversity.

\section{Introduction}

Ecologists have appreciated for a long time that there is a positive relationship between the area of a region and how many species can be found in it (Arrhenius 1921; Gleason 1922; Preston 1962). This relationship (called a species-

\footnotetext{
* Email: jsoberon@ku.edu. ORCIDs: Soberón, https://orcid.org/0000-0003-2160-4148.
}

Am. Nat. 2019. Vol. 194, pp. 760-775. ( 2019 by The University of Chicago. 0003-0147/2019/19406-58690\$15.00. All rights reserved. DOI: $10.1086 / 705898$ area relationship, or SAR) has been described by a variety of mathematical shapes (Lomolino 2000; Tjørve 2003) and explained by sampling effects, larger number of individuals with increasing area, more habitats included in larger areas, and other causes (Rosenzweig 1995). Some argue that there is a single SAR (Storch et al. 2012), others that there is no single simple mathematical shape that can describe the relationship (Harte 2011). Moreover, the underlying mechanisms determining a SAR change with scale (Williams 1964; Rosenzweig 1995; Drakare et al. 2006) and may be better described using demography, individual movements and habitat factors at small extents, and geography, climate, barriers, and large evolutionary factors at larger extents.

In this contribution, I analyze SARs at a biogeographic scale (extents of $10^{6}$ to $10^{7} \mathrm{~km}^{2}$ and resolutions of grids of $10^{2}$ to $10^{3} \mathrm{~km}^{2}$ ) using the amount of climatic space as the predictor (Meyer and Pie 2018). The approach is based on theoretical ideas related to Grinnellian niches (Jackson and Overpeck 2000; Soberón and Peterson 2005; Colwell and Rangel 2009; Peterson et al. 2011). Grinnellian niches mean essentially two things. First, niche spaces are composed of scenopoetic variables (Hutchinson 1978), that is, variables that are not dynamically linked (via feedback loops) to population fluctuations even though they affect the fitness of a population. They are conditions for existence (Begon et al. 2006) rather than resources to be exploited. This leads directly to the use of set theoretical language and to a computational approach rather than to the analytic approaches (isoclines in phase spaces) required by niches defined using interacting variables (Chase and Leibold 2003). Second, Grinnellian niches are naturally oriented to analyze biogeographic questions in realistic geographic regions (i.e., no arbitrary rectangular or toroidal arenas), defined explicitly and subdivided by a discrete grid of extent and resolution suitable to address biogeographic questions (Shmida and Wilson 1985). This perspective relies on the one-to-one relationship between the cells in the grid and the set of vectors of scenopoetic variables. A one-to-one relationship is possible if enough variables, at enough precision, are used to characterize the environmental space (Aspinall and Lees 1994). This is the original idea of a biotope (Hutchinson 1957), later christened "Hutchinson's duality" by Colwell 
and Rangel (Colwell and Rangel 2009; Soberón and Nakamura 2009).

Grinnellian niche theory relates in an explicit and operational way areas of distribution and niches (Soberón 2007; Peterson et al. 2011) and thus provides a natural framework to analyze SARs at large scales. From this perspective, the driving factor of the SAR is not the distribution of the number of individuals as a function of area (Preston 1962; May 1975; O’Dwyer and Green 2010) nor the distribution of areas of different size in geography (Coleman 1981; Allen and White 2003; Leitner and Rosenzweig 2003) but the distribution of fundamental niches in niche space and how they intersect with subregions of niche space of different measure (in set theory, this is a number representing the size of a set). Instead of assuming infinite arenas and arbitrary or random distributions for the shapes and positions of niches, I will derive them from data, and the region is of finite size.

Although the Grinnellian niche approach is unequivocally empirical in that it requires large quantities of data, several theoretical assumptions are needed to apply it to the SAR problem. First, a sequence of larger and larger regions $\mathbf{R}$ is used, for which a variety of measures of size (including area) can be taken. Specifically, I will be interested in how "niche space" increases with larger regions, which requires a definition of niche space size (see below). Second, I assume that there are no barriers to dispersal, so if a geographic cell has a suitable environment for a species, the species will occupy it. This is called a "Hutchinson's world" in the terminology of Owens et al. (2013). Of course, this is an assumption known to be false in many cases (Svenning and Skov 2004), but relaxing it requires modeling dispersal, something that, although feasible (Rangel et al. 2007; Qiao et al. 2016), complicates things substantially (for instance, hypotheses about the initial conditions per species are needed). Therefore, for illustration purposes, it is assumed that the geographic extent of continental North America (sensu lato) has been accessible to the group of interest, the terrestrial mammals. Third, I will assume that there are no interactions among species, which will allow estimating the species composition of a region simply by stacking independently calculated distributions (Cooper and Soberón 2018). This may be called a Gleasonian ecology. Again, there are biological (Leathwick 1998; Gutiérrez et al. 2014) and technical (Calabrese et al. 2014) limitations to this assumption, but to relax it one needs data (and theory) on the results of interactions, a nontrivial problem. Moreover, at coarse spatial resolutions interactions may not be universally important (Soberón 2010). Finally, I assume that niches are of convex shape (Maguire 1973; Cohen 1978; Drake 2015) and (for each species) conserved in time and space (Holt and Gomulkiewicz 1997; Wiens and Donoghue 2004; Peterson 2011), thus disregarding evolution. Assuming no dispersal limitations, noninteracting species and conserved fundamental niches constitute some sort of null model for biogeography
(NMB; Qiao et al. 2016; Ulrich et al. 2017), and one in which the actual shapes of the geographic and environmental space play a fundamental role.

\section{Modeling the Niches}

The large number of symbols used in this article are summarized in table 1 . When a grid has been established in geographic space, it is an easy task to obtain environmental values for its cells and then characterize those geographic points where a species has been reported to exist. This is called environmental niche modeling, and it is illustrated in figure 1, in two climatic variables for the case of the clade of the felids of North America. Niches are modeled using ellipsoids (see "Methods"). In figure 1 it is shown how climate combinations (symbolized by $\boldsymbol{v}$ ) where species $j$ has been observed to exist can be used to model a shape defining a hypothetical fundamental niche of $j$.

We assume the ellipsoids are estimates of fundamental niches. This should be interpreted as follows: Each species has a function mapping environments to fitness. The fundamental niche is the level curve of minimum fitness compatible with existence (the value of 1 if fitness is measured using the finite rate of increase; see Drake [2015] for a similar idea and Holt [2009] for some clarifying remarks on the issue), without interspecific interactions. These curves are represented as ellipses $\left(\mathbf{F}_{j}\right)$. Although normally we do not know the fundamental niches, Hutchinson (1957) hypothesized that the environments in the actual observed niche (the realized) should be inside the fundamental (Soberón and Arroyo-Peña 2017), and thus one way of providing a lower bound for $\mathbf{F}_{j}$ is by drawing a convex shape, like an ellipsoid, around the observations. Other authors have used ellipsoids to represent realized niches (Ulrich et al. 2017), but we specifically use them as models for the fundamental niche.

The climates in region $\mathbf{R}$ constitute a set of vectors $\mathbf{E}_{\mathbf{R}}(t)=\left\{\boldsymbol{\nu}_{i} \mid i \in \mathbf{R}\right\}$. Each point $i$ in the grid has a corresponding "point," or vector of environmental variables $\boldsymbol{v}_{i}$. If a point $\boldsymbol{v}_{i}$ is inside an $\mathbf{F}_{j}$, that climate is assumed to be favorable (allows a fitness higher than the threshold) for species $j$, and therefore the species will be present in the locality corresponding to point $i$. Therefore, the set of points inside the shape $\mathbf{F}_{j}$ constitute (by the assumption of dispersal equilibrium) all of the climates in its area of distribution: $\mathbf{F}_{j}^{*}=$ $\left\{i \mid \boldsymbol{v}_{i}\right.$ is included in $\left.\mathbf{F}_{j}\right\}$, and the measure of this set $\left|\mathbf{F}_{j}^{*}\right|=$ $W_{j}$ is the amount of niche space occupied by the species. The proportion relative to the total size of niche space is denoted by $w_{j}$. Correspondingly, for a given point $\boldsymbol{v}_{i}$ in niche space, the number of niches that contain the point represent the local species richness for that environmental combination: $\boldsymbol{\alpha}\left(\boldsymbol{v}_{i}\right)=\mid\left\{j \mid \mathbf{F}_{j}\right.$ contains $\left.\boldsymbol{v}_{i}\right\} \mid$. 
Table 1: Symbols, names, and conceptual explanation of the main terms used in the article

\begin{tabular}{|c|c|c|c|}
\hline Symbol & Name & Concept & Equation \\
\hline G & Geographic space & $\begin{array}{l}\text { A grid of cells of a given extent, form, } \\
\text { resolution, and projection, representing } \\
\text { the total area of interest. This is a dis- } \\
\text { crete set assumed to be constant in time. }\end{array}$ & $\mathbf{G}=\left\{\left(x_{i}, y_{i}\right)\right\}$ \\
\hline $\mathbf{R}(t)$ & $\begin{array}{l}\text { Subregion in } \\
\text { geographic space }\end{array}$ & $\begin{array}{l}\text { A subset of } \mathbf{G} \text { (a discrete set). This set may } \\
\text { change in time. Its measure }|\mathbf{R}| \text { is } \\
\text { simply the number of its elements. }\end{array}$ & $\mathbf{R}=\left\{\left(x_{i}, y_{i}\right)\right\} \subseteq \mathbf{G}$ \\
\hline $\mathbf{E}_{\mathbf{R}}(t)$ & $\begin{array}{c}\text { Environments in } \\
\text { a subregion }\end{array}$ & $\begin{array}{l}\text { The set of environmental combinations } \\
\text { existing in a region } \mathbf{R} \text {. This can be a } \\
\text { discrete set of multivariate elements } \\
\text { with } d \text { dimensions or a continuous } \\
\text { representation using density kernels. The } \\
\text { multivariate elements }(\boldsymbol{\nu}) \text { are the sceno- } \\
\text { poetic variables used (e.g., BioClim var- } \\
\text { iables). Environmental combinations may } \\
\text { change in time. The kernel representa- } \\
\text { tion is a probability density, integrating } \\
\text { to } 1 .\end{array}$ & $\begin{array}{l}\mathbf{E}_{\mathbf{R}}=\left\{\boldsymbol{\nu}_{i} \mid\left(x_{i}, y_{i}\right) \in \mathbf{R}\right\} \\
\mathbf{E}_{\mathbf{R}}(\nu ; t)=\frac{1}{|h|} \sum_{i=1}^{n} K_{h}\left(\nu-\nu_{i}\right)\end{array}$ \\
\hline$\left|\mathbf{E}_{\mathbf{R}}(t)\right|$ & $\begin{array}{l}\text { The size, or "mea- } \\
\text { sure," of the envi- } \\
\text { ronmental space }\end{array}$ & $\begin{array}{l}\text { The amount of available environmental } \\
\text { space in a region } \mathbf{R} \text { at time } t \text {. A dimen- } \\
\text { sional magnitude, with units depending } \\
\text { on the bandwidth of the kernel. }\end{array}$ & \\
\hline$\varphi_{j}(\boldsymbol{\nu})$ & $\begin{array}{l}\text { Fitness function for } \\
\text { species } j \text { as a } \\
\text { function of the } d \\
\text { environments }\end{array}$ & $\begin{array}{l}\text { A function that maps, for species } \\
j=1,2, \ldots, S \text {, environments into } \\
\text { fitness. For a suitable threshold in } \\
\text { fitness, this is the function that } \\
\text { determines a fundamental niche. }\end{array}$ & $\varphi_{j}(\boldsymbol{\nu}): \mathbb{R}^{d} \rightarrow \mathbb{R}$ \\
\hline $\begin{array}{l}\mathbf{F}_{j}(\boldsymbol{\nu})= \\
\quad\left\{\boldsymbol{v} \mid \varphi_{j}(\boldsymbol{\nu})>k\right\}\end{array}$ & $\begin{array}{l}\text { The fundamental } \\
\text { niche of species } j\end{array}$ & $\begin{array}{l}\text { The fundamental niche of species } j \text {. } \\
\text { This is the set of all environmental } \\
\text { combinations for which fitness is } \\
\text { higher than the threshold. It can be a } \\
\text { continuous function, but often it is } \\
\text { represented as a simple presence- } \\
\text { absence function. It has a border for } \\
\text { the contour level }=k \text {. }\end{array}$ & $\mathrm{F}_{j}: \mathbb{R}^{d} \rightarrow\{0,1\}$ \\
\hline $\mathbf{F}_{j}^{*}(t)$ & $\begin{array}{l}\text { The existing niche } \\
\text { of species } j\end{array}$ & $\begin{array}{l}\text { The set of all environmental combinations } \\
\text { that both (1) are part of the fundamental } \\
\text { niche and (2) also exist in } \mathbf{R} \text { at time } t \text {. It } \\
\text { can be defined over a continuous or a } \\
\text { discrete representation of } \mathbf{E} \text {. }\end{array}$ & $\mathbf{F}_{j}^{*}(t): \mathbb{R}^{d} \cap \mathbf{E}_{\mathbf{R}}(t) \rightarrow\{0,1\}$ \\
\hline $\mathbf{F}$ & $\begin{array}{l}\text { A set of fundamental } \\
\text { niches }\end{array}$ & $\begin{array}{l}\text { All of the fundamental niches of a group of } \\
\text { species, defined by any means (ecologi- } \\
\text { cally, phylogenetically, economically). }\end{array}$ & $\mathbf{F}=\left\{\mathbf{F}_{j} j=1, \ldots, S\right\}$ \\
\hline$w_{j}(t)$ & $\begin{array}{l}\text { The proportional } \\
\text { size of the existing } \\
\text { niche }\end{array}$ & $\begin{array}{l}\text { This is a measure of what proportion of } \\
\text { environmental space is occupied by spe- } \\
\text { cies } j \text {. Because of Hutchinson's duality } \\
\text { and the assumption of dispersal capaci- } \\
\text { ties, it is also a measure of proportional } \\
\text { range size. It can be defined for contin- } \\
\text { uous or discrete representations of E. } \\
\text { Notice that in the continuous case, the } \\
\text { multiple integral is taken over the region } \\
\text { defined by the fundamental niche. }\end{array}$ & $\begin{array}{l}w_{j}(t)=\frac{1}{|R|} \sum_{i=1}^{n} F_{j}^{*}(t) \\
w_{j}(t)=\int_{\mathbf{F}_{j}} \mathbf{E}_{\mathbf{R}}(\boldsymbol{\nu} ; t) \mathrm{d} \boldsymbol{\nu}\end{array}$ \\
\hline
\end{tabular}


Table 1 (Continued)

\begin{tabular}{|c|c|c|c|}
\hline Symbol & Name & Concept & Equation \\
\hline$\alpha(\boldsymbol{\nu} ; t)$ & $\begin{array}{l}\text { The local number } \\
\text { of species at a } \\
\text { neighborhood of } \\
\text { environmental } \\
\text { combination } \nu\end{array}$ & $\begin{array}{l}\text { The measure of local or alpha diversity. A } \\
\text { count of number of species in a particular } \\
\text { combination of environments. It is cal- } \\
\text { culated using an indicator function } I_{j}(\boldsymbol{\nu}) \\
\text { that is } 1 \text { if environment } \boldsymbol{\nu} \text { is inside the } \\
\text { fundamental niche of species } j \text { and } 0 \\
\text { otherwise. The time is explicit to empha- } \\
\text { size the fact that environmental combin- } \\
\text { ations change in time. }\end{array}$ & $\alpha(\boldsymbol{\nu})=\sum_{j=1}^{s} I_{j}(\boldsymbol{\nu} ; t)$ \\
\hline $\bar{w}_{\mathrm{R}}(t)$ & $\begin{array}{l}\text { The mean existing } \\
\text { niche for all spe- } \\
\text { cies in a region } \mathbf{R} \\
\text { at time } t\end{array}$ & $\begin{array}{l}\text { This is the average of the existing niche } \\
\text { measures for all species present in } \mathbf{R} \text {. } \\
\text { Because of Hutchinson's duality and the } \\
\text { assumptions of the NMB, this is also } \\
\text { equivalent to the mean range size in } \\
\text { geographic space. }\end{array}$ & $\bar{w}(t)=\frac{1}{S} \sum_{j=1}^{S} w_{j}(t)=\frac{1}{S} \sum_{j=1}^{S} \int_{\mathrm{F}_{j}} \mathbf{E}_{\mathbf{R}}(t) \mathrm{d} \nu$ \\
\hline $\bar{\alpha}_{\mathbf{R}}(t)$ & $\begin{array}{l}\text { The mean local } \\
\text { (alpha) species } \\
\text { number at time } t \\
\text { over the region } \mathbf{R}\end{array}$ & $\begin{array}{l}\text { This is the mean alpha diversity in the } \\
\text { region } \mathbf{R} \text {. It is taken by integrating the } \\
\text { local alpha diversity over all environ- } \\
\text { mental space, weighted by the propor- } \\
\text { tional abundance of a particular envi- } \\
\text { ronmental combination. }\end{array}$ & $\bar{\alpha}_{\mathbf{R}}(t)=\int_{\mathbf{R}} \mathbf{E}_{\mathbf{R}}(\boldsymbol{\nu} ; t) \alpha(\boldsymbol{\nu}) \mathrm{d} \boldsymbol{\nu}$ \\
\hline
\end{tabular}

Note: The integrals are multiple integrals, taken over the appropriate $d$-dimensional environmental space. All sets and vectors are written using boldface. $\mathrm{NMB}=$ null model for biogeography.

\section{Presence-Absence Matrices (PAMs) and Whittaker and MacArthur Equations}

When considering many species, the overlay of the grid representation of areas of distribution implies a PAM of $N$ sites by $S$ species $\mathbf{X}=\left[\delta_{i, j}\right]$, with elements equal to 1 if species $j$ is present in cell $i$ and 0 otherwise. PAMs can be estimated from the extent of occurrence maps of a group of species (Soberón and Ceballos 2011; Storch et al. 2012; Vilela and Villalobos 2015). A well-sampled geographic PAM contains all of the information about species incidences and coincidences and thus, implicitly, all incidence-based indices (Soberón and Cavner 2015). Specifically, the local number of species (alpha diversity), the total number of species (gamma diversity), and their ratio, called beta diversity, are related as follows (Whittaker 1960):

$$
\frac{\bar{\alpha}(\mathbf{R})}{S(\mathbf{R})}=\beta(\mathbf{R}) \equiv \frac{\bar{\omega}(\mathbf{R})}{|\mathbf{R}|},
$$

where $S(\mathbf{R})$ is the total number of species, $\bar{\alpha}(\mathbf{R})$ is the average number of species in region $\mathbf{R}$, and $\bar{\omega}(\mathbf{R})$ is the average range size of the species. This equality can be derived directly from a geographic PAM (Routledge 1977; Schluter and Ricklefs 1993; Arita et al. 2008).

PAMs can also be defined for niche space (Ulrich et al. 2017), and it is not widely appreciated that equation (1), de- rived for geographic space, has a niche space version, due to MacArthur (1972). He related the total number of species in a community present in a region $\mathbf{R}$; the amount of niche space (one dimensional, in the original derivation) available in $\mathbf{R}$, hereby denoted as $\left|\mathbf{E}_{\mathbf{R}}\right|$; and the amount of niche overlap among species. The average niche usage of the species present in $\mathbf{R}$ is $\bar{W}(\mathbf{R})$, the average amount of overlap among niches is $\bar{O}(\mathbf{R})$, and MacArthur derived the following identity:

$$
S(\mathbf{R})=\frac{\left|\mathbf{E}_{\mathbf{R}}\right|}{\bar{W}(\mathbf{R})}[1+\bar{O}(\mathbf{R})]
$$

MacArthur did not present data related to equation (2) and used it mostly as a conceptual framework to discuss a number of general problems. However, under the assumptions of the NMB and for scenopoetic variables, it is possible to calculate the components of MacArthur's equation, realistically and for large numbers of species. For any given region, its climatic space can be sampled, and a continuous smooth $\mathbf{E}_{\mathbf{R}}(\boldsymbol{v})$ kernel can be fitted (Petitpierre et al. 2012; Blonder et al. 2014 ), as shown in figure 2. The measure of $\mathbf{E}_{\mathbf{R}}(\boldsymbol{v})$ can also be obtained. The measure I use is a metric of how spread a distribution is. A uniform distribution over the range of values of the variables would have the maximum measure, 

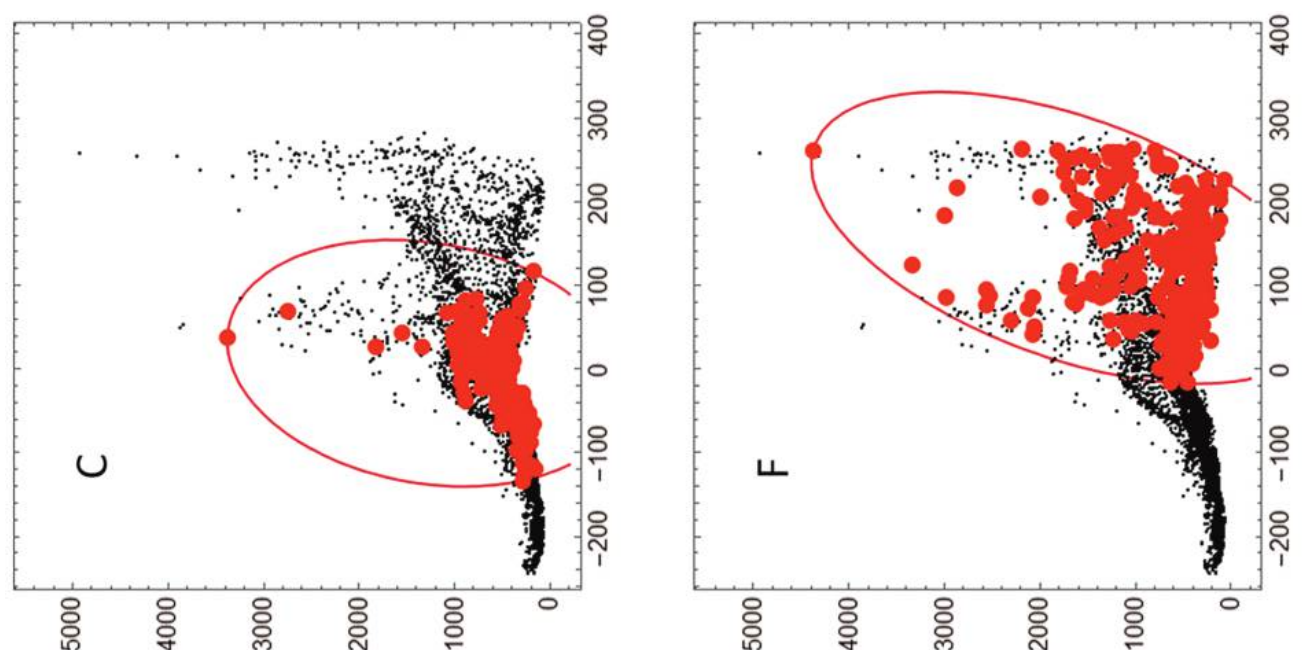

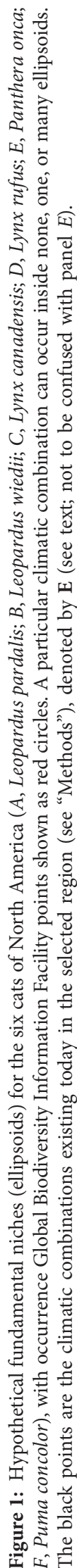
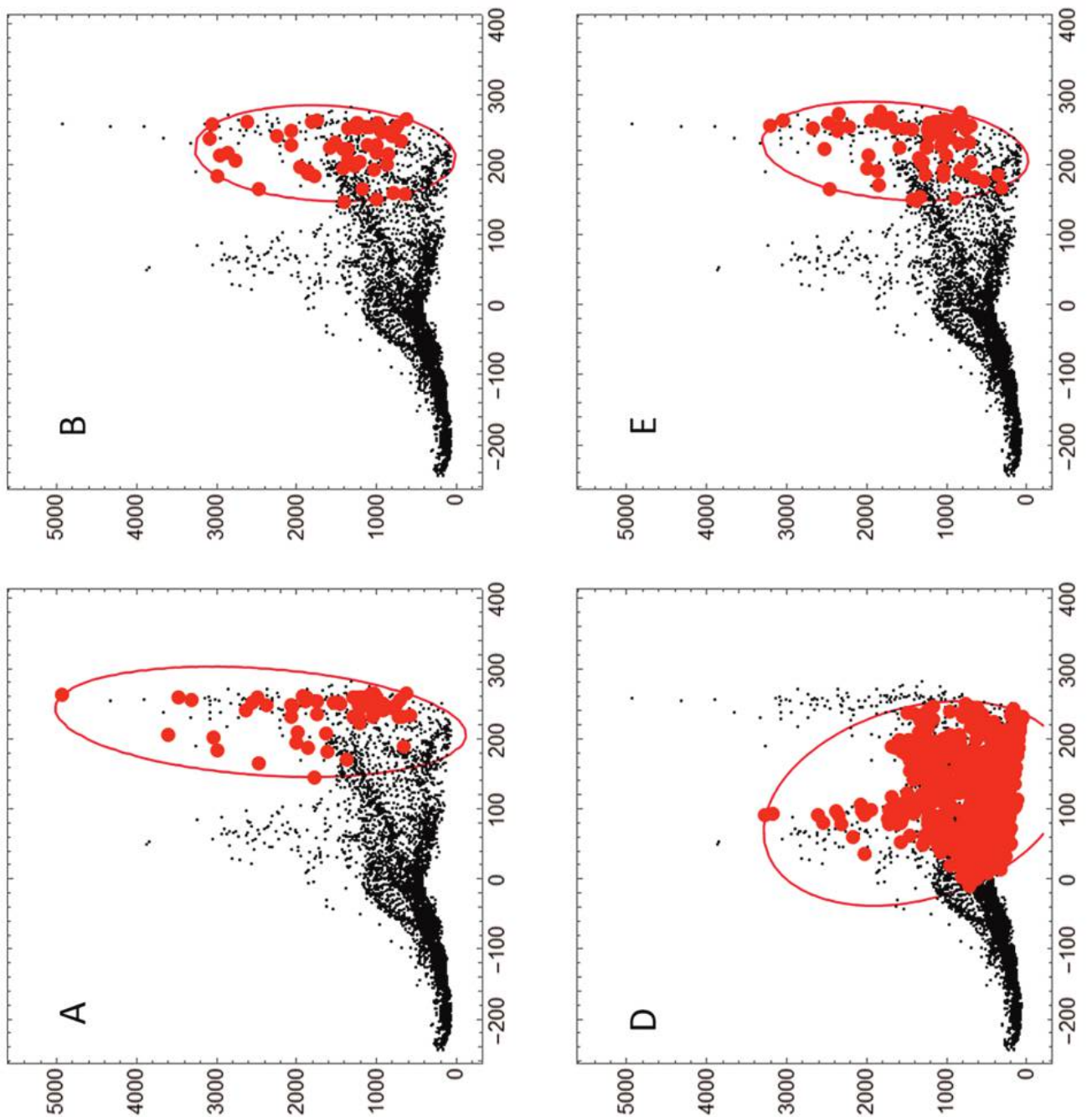

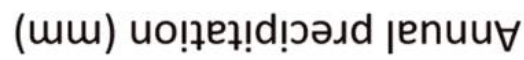

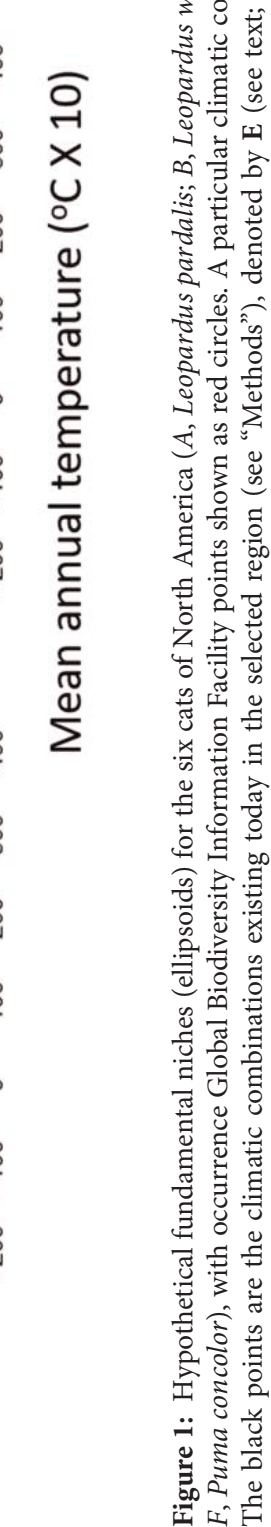

This content downloaded from 129.237.090.146 on February 11, 2020 06:05:23 AM 

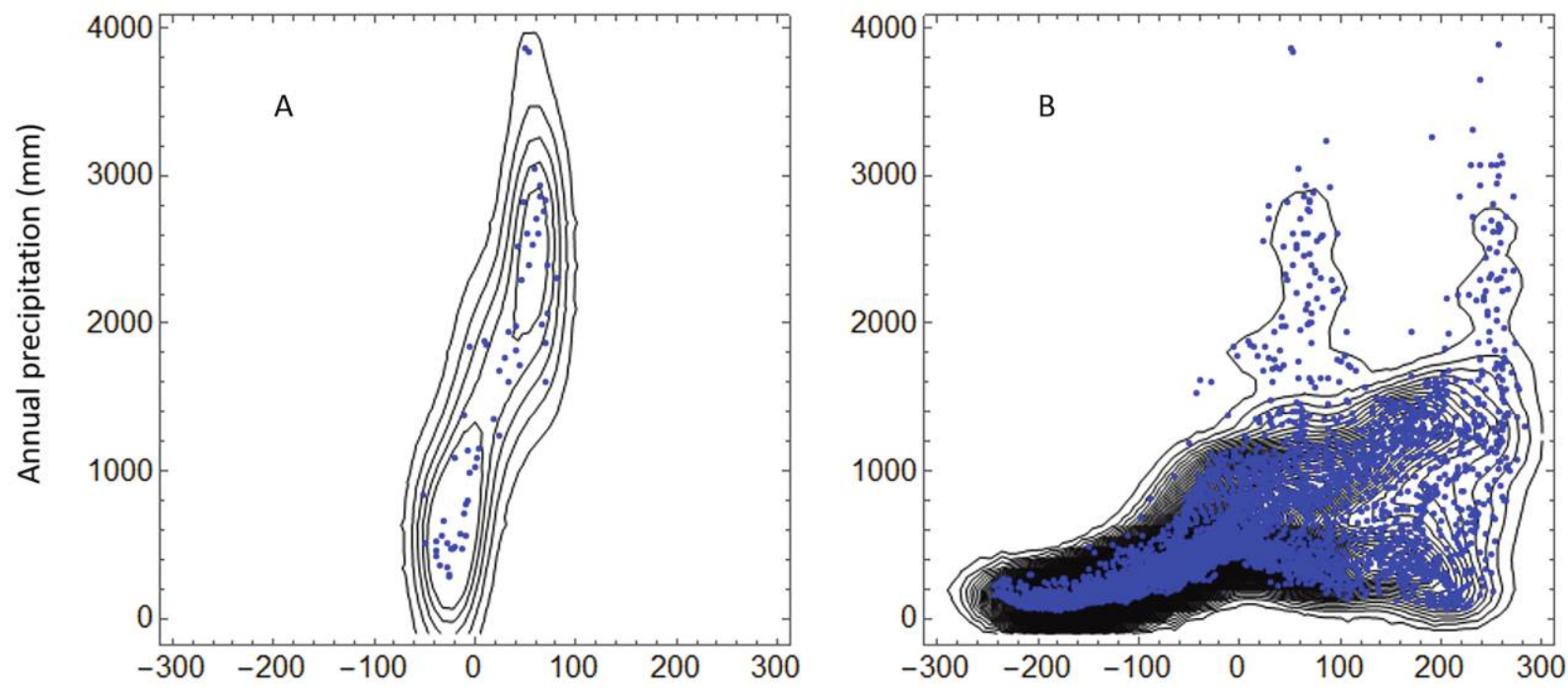

Mean annual temperature $\left({ }^{\circ} \mathrm{C} \times 10\right)$

Figure 2: Continuous kernel probability densities fitted to two regions $(\mathbf{R})$ of the North American climate space $\left(\mathbf{E}_{\mathbf{R}}\right)$ in two variables. Panel $A$ shows a fit to 60 points in British Columbia, and panel $B$ shows a fit to 5,044 points in the entire extent of North America. The measure $\left(\left|\mathbf{E}_{\mathbf{R}}\right|\right.$; see "Methods") of the distribution in panel $A$ is $3.17 \times 10^{4}$, and that in panel $B$ is $1.44 \times 10^{6}$, both with units of $\left({ }^{\circ} \mathrm{C} \times \mathrm{mm}\right)^{1 / 2}$.

and a spike over a narrow region would have a small measure (see "Methods").

If we represent the fundamental niches of species using shapes (ideally convex) that separate the environmental space in regions inside and outside the niche $\mathbf{F}_{j}(\boldsymbol{v})$, then the size of existing niche space used by species $j$ is

$$
\begin{aligned}
W_{j}(\mathbf{R}) & =\omega_{j}(\mathbf{R})\left|\mathbf{E}_{\mathbf{R}}\right|, \\
\omega_{j}(\mathbf{R}) & =\int_{\mathbf{F}_{j}} \mathbf{E}_{\mathbf{R}}(\boldsymbol{v}) \mathrm{d} \boldsymbol{v} .
\end{aligned}
$$

The symbol $W_{j}(\mathbf{R})$ denotes the amount of total niche space in region $\mathbf{R}$ actually occupied by species $j$, and $\omega_{j}(\mathbf{R})$ denotes the proportion of niche space. Both are measures of niche breadth, and under the assumptions of the NMB, $W_{j}(\mathbf{R})$ is equivalent to the size of the distributional range. The quantity $\omega_{j}(\mathbf{R})$ is called the existing niche (Jackson and Overpeck 2000; Peterson et al. 2011). The integral symbol means the multiple integral taken over the region inside the contour curve (or surface) defining the fundamental niche of species $j$ in multidimensional space. Given the region $\mathbf{R}$ and the set of niches $\mathbf{F}$, calculations can be performed to obtain the different quantities in equation (3). Among the several possible numbers that can be used as measures of the set $\mathbf{R}$ (Triantis et al. 2003; Nogués-Bravo and Araújo 2006), I will use the amount of environmental space in $\mathbf{R}$ as described above and in figure 2.

Equation (3) expresses the proportion of available climatic space inside the shape defining the fundamental niche of species $j$, a measure of niche breadth in relation to available environments in $\mathbf{R}$ (Jackson and Overpeck 2000; Soberón and Arroyo-Peña 2017). The average over all of the species is

$$
\bar{\omega}(\mathbf{R})=\frac{1}{S(\mathbf{R})} \sum_{j=1}^{S} \omega_{j}(\mathbf{R})=\frac{1}{\left|\mathbf{E}_{\mathbf{R}}\right|} \bar{W}(\mathbf{R}),
$$

which is the reciprocal of the first term in MacArthur's equation (2).

To estimate the second term, the number of overlapping niches at the point $v$, I use an indicator function per species (Drake 2015), $I_{j}(\boldsymbol{v})$, with a value of 1 if the environmental combination $v$ is inside the fundamental niche of the species $j$ and 0 otherwise. With this definition, the number of overlaps around $v$ becomes

$$
O(\boldsymbol{v})=\sum_{j=1}^{S} I_{j}(\boldsymbol{v})-1
$$

And its expected value over all of the environments in the region is 


$$
\begin{aligned}
\bar{O}(\mathbf{R}) & =\int_{R} O(\boldsymbol{v}) \mathbf{E}_{\mathbf{R}}(\boldsymbol{v}) \mathrm{d} \boldsymbol{v} \\
& =\int_{R}\left[\sum_{j=1}^{S} I_{j}(\boldsymbol{v})\right] \mathbf{E}_{\mathbf{R}}(\boldsymbol{v}) \mathrm{d} \boldsymbol{v}-\int_{R} \mathbf{E}_{\mathbf{R}}(\boldsymbol{v}) \mathrm{d} \boldsymbol{v} \\
& =\int_{R}\left[\sum_{j=1}^{S} I_{j}(\boldsymbol{v})\right] \mathbf{E}_{\mathbf{R}}(\boldsymbol{v}) \mathrm{d} \boldsymbol{v}-1 \\
& =\int_{R} \alpha(\boldsymbol{v}) \mathbf{E}_{\mathbf{R}}(\boldsymbol{v}) \mathrm{d} \boldsymbol{v}-1 \\
& =\bar{\alpha}(\mathbf{R})-1 .
\end{aligned}
$$

The sum in equation (6) represents the number of niches that contain environmental combination $v$, which equates to the number of species around the local region $v$. This is the alpha diversity $\alpha(v)$, and its integral over the environments in region $\boldsymbol{R}$, weighted by the density kernel $\mathrm{E}_{\mathrm{R}}$, yields the average local diversity in the region:

$$
\int_{R} \alpha(\boldsymbol{v}) \mathbf{E}_{\mathbf{R}}(\boldsymbol{v}) \mathrm{d} \boldsymbol{v}=\bar{\alpha}(\mathbf{R})
$$

Substituting equations (6) and (4) into equation (2) yields MacArthur's equation in terms that can be calculated from $\mathbf{R}$ and $\mathbf{F}$ :

$$
S(\mathbf{R})=\frac{\left|\mathbf{E}_{\mathbf{R}}\right|}{\bar{\omega}(\mathbf{R})} \bar{\alpha}(\mathbf{R}) .
$$

It is very interesting that MacArthur's equation, in Grinnellian terms, hinges on the fact that the integral (over the entire environmental space) of the indicator function of a given species, weighted by the density $\mathbf{E}_{\mathbf{R}}(\boldsymbol{v})$, equals the integral of $\mathbf{E}_{\mathbf{R}}(\boldsymbol{v})$ over the fundamental niche of the species:

$$
\int_{R}\left[I_{j}(\boldsymbol{v})\right] \mathbf{E}_{\mathbf{R}}(\boldsymbol{v}) \mathrm{d} \boldsymbol{v}=\int_{\mathrm{F}_{j}} \mathbf{E}_{\mathbf{R}}(\boldsymbol{v}) \mathrm{d} \boldsymbol{v} .
$$

Therefore, the average alpha diversity (the average taken over all environmental space) equals the sum of proportional niche breadths taken over all species:

$$
\begin{aligned}
\int_{R} \alpha(\boldsymbol{v}) \mathbf{E}_{\mathbf{R}}(\boldsymbol{v}) \mathrm{d} \boldsymbol{v} & =\bar{\alpha}(R) \\
& =\sum_{j=1}^{S(R)} \int_{\mathbf{F}_{j}} \mathbf{E}_{\mathbf{R}}(\boldsymbol{v}) \mathrm{d} \boldsymbol{v} \\
& =S(R) \bar{\omega} .
\end{aligned}
$$

Notice that in the original derivation of MacArthur (1972) the number of overlappings in niche space was considered a measure of the strength of competition, but in the NMB we are assuming that interactions do not have an effect at coarse scales, and thus "overlaps" are a measure of local coexistence, or alpha diversity.

Equation (8) has numerous implications for biogeography, and this is what we use to analyze SARs from a niche perspective. The key observation, worth repeating, is that under the $\mathrm{NMB}$, equation (8) implies that the average proportional species richness equals the average proportional area of distribution, which is the equivalent of Whittaker's beta diversity in niche space:

$$
\frac{\bar{\alpha}(\mathbf{R})}{S(\mathbf{R})}=\frac{\bar{W}(\mathbf{R})}{\left|\mathbf{E}_{\mathbf{R}}\right|}=\bar{\omega}(\mathbf{R}) \equiv \frac{1}{\beta(\mathbf{R})} .
$$

Despite the fact that equation (11) is a simple mathematical consequence of the definitions, it shows that biodiversity patterns can be interpreted equivalently in terms of local distribution of richness or global amount of niche space occupied. The driving factors (under the assumptions of the $\mathrm{NMB}$ ) are the size and structure of environmental space in a region and the position and size of the physiological set of tolerances (the fundamental niches) of a set of species. This is the idea explored in this article: niche breadths (which can be estimated using scenopoetic variables for thousands of species) are related to range sizes, and the dynamics of the relationship is driven by climate as a forcing factor.

\section{The Relationship between Alpha and Beta Diversity and the SAR}

Equation (8) relates the total number of species in a region to the local numbers and the mean niche breadths. How should $\bar{\alpha}(\mathbf{R})$ and $\bar{\omega}(\mathbf{R})$ change when $\mathbf{R}$ grows? The answer depends on the relationship among the position, structure, and size of niche space in $\mathbf{R}$, expressed by the kernel $\mathbf{E}_{\mathbf{R}}$, in relation to the location in niche space of the set of fundamental niches $\mathbf{F}=\left\{\mathbf{F}_{1}, \ldots, \mathbf{F}_{s}\right\}$ of the pool of species (Ulrich et al. 2017). When $\mathbf{R}$ expands, $\bar{\alpha}(\mathbf{R})$ and $\bar{\omega}(\mathbf{R})$ - and therefore the total number of species $S(\mathbf{R})$ - change, depending on the specifics of the location of the fundamental niches with respect to the trajectory of expansion of niche space with area. If one creates a sequence of regions from small to large, in nested, random, abutting, or whatever fashion (Rosenzweig 1995; Drakare et al. 2006; Scheiner et al. 2011), the actual configuration of the environments in the sequence, in relation to F, will strongly influence the shape of a SAR (Harte 2011, p. 42). This is illustrated in figure 3 , using the six species in the cat's family. Starting in a large region of low diversity (fig. 3, British Columbia, point A) should produce a very contrasting SAR to one that begins in a very species-rich region of small size (fig. 3, Panama, point B). The particular way in which the changes take place should depend on the actual path in which $\mathbf{R}$ grows in relation to the position of $\mathbf{F}$.

Although both $\bar{\alpha}(\mathbf{R})$ and $\bar{\omega}(\mathbf{R})$ change with the region $\mathbf{R}$, there is an important difference. Since $\bar{\omega}(\mathbf{R})$ is the average 


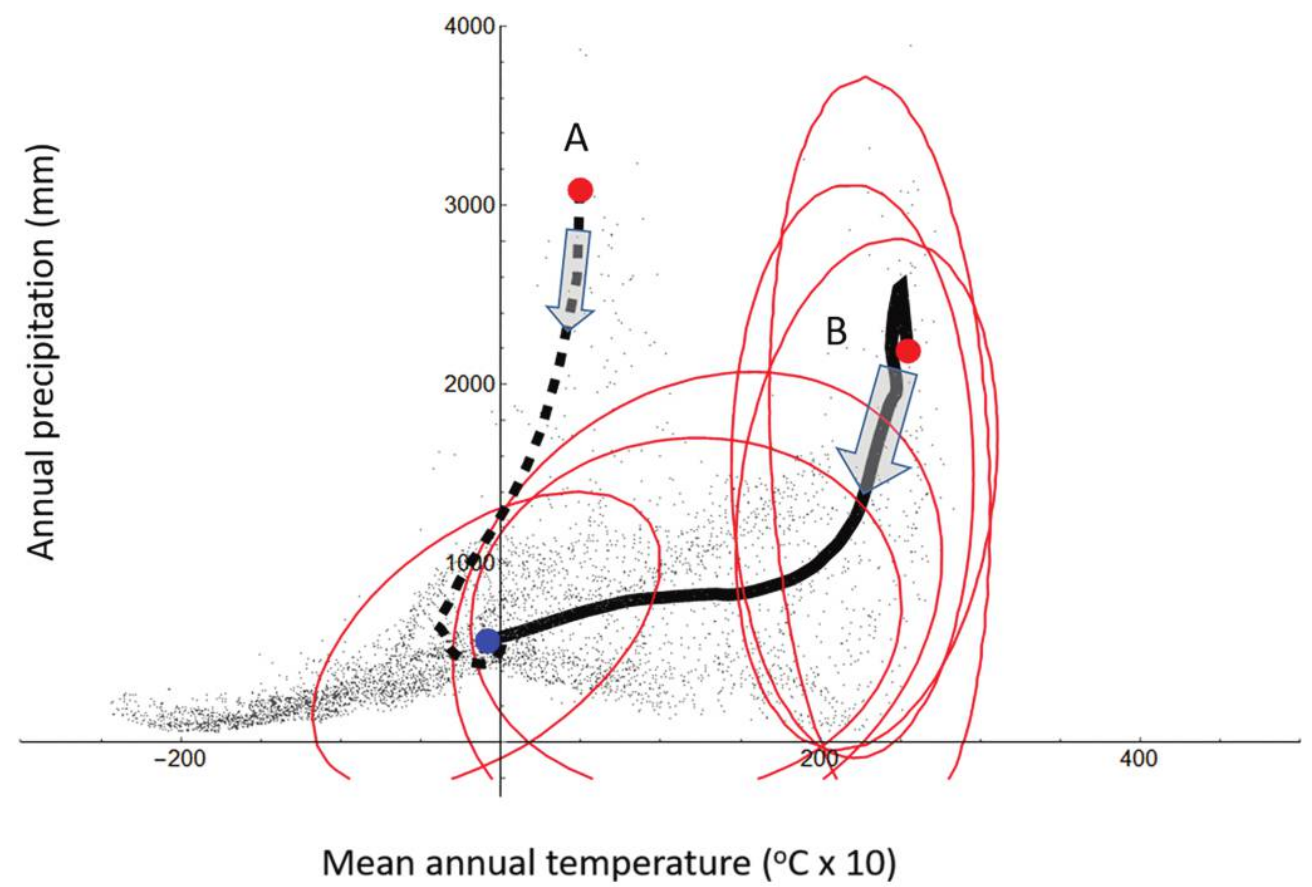

Figure 3: Paths of growth of two regions (solid and broken lines) and fitted niches ( $\mathbf{F}_{j}$; hypothetically fundamental) for the six North American species of the family Felidae. The lines trace the mean values of the two variables for regions of increasing sizes. Red circles show the starting positions for two paths of increasing amount of niche space. Point A begins in British Columbia and point B in Panama, and the arrows indicate the direction of growth of $\mathbf{E}_{\mathrm{R}}$. The blue circle shows the mean value of the two variables for all of North America. The black points show the climatic composition of the 5,044 cells in the entire grid of North America.

proportion of niche space occupied, by increasing the size of $\mathbf{R}$ one would expect that the average proportion of climate space used by the species should decrease, because in small regions, whatever species live there probably occupy most of the available niche space. However, with increasing size of the region, environmental space grows and the mean occupied proportion should diminish.

The mean local richness, $\bar{\alpha}(\mathbf{R})$, on the other side, is a number defined locally, and it may or may not depend on the size of $\mathbf{R}$. It can grow with increased $\mathbf{R}$ if larger regions include more fundamental niches and thus larger pools of species (Carstensen et al. 2013), as in path B of figure 3, or stay largely constant if the larger regions are mostly composed of environments favorable to the same set of species, as in path A. In other words, whether niche space in larger $\mathbf{R}$ overlaps with more or less fundamental niches depends on the position of $\mathbf{R}$ relative to the locations and sizes of the set of fundamental niches (fig. 3).

Finally, as has been pointed out (Williamson et al. 2001), both the planet and the pool of species are of finite size, and thus both axes in any comprehensive SAR are bounded. From the above, the predictions below follow.

Prediction 1. In a sequence of regions of increasing size, the average alpha diversity should not have a preferred way of changing, but the beta diversity (the reciprocal of the proportion of occupied niche space) should increase: it is beta diversity that changes with area.

Prediction 2. In nested Rs, the precise way in which the Rs are constructed matters very much (Storch et al. 2003). In fact, the specific sequence determines the shape of the SAR. How alpha and beta diversity change depends on the path, since they depend on where $\mathbf{F}$ is in relation to $\mathbf{E}$. However, in a random sequence of regions, the effect of the path on alpha diversity should be much less important. In any case, all comprehensive SARs will end at the point of maximum coverage and maximum number of species considered.

Prediction 3. When creating a SAR at biogeographic scales, what should matter is the increase in niche space rather than area per se. In other words, the correlation of species numbers against niche volume should be better than that against geographic area.

Prediction 4. The slope of the SAR depends on the rate at which climate space (modeled by the density kernel) enters or leaves $\mathbf{F}$. For instance, the change in slope in the Alaska curve is due to a large amount of niche space entering into contact with $\mathbf{F}$, that is, the relationship between alpha diversity and $\mathbf{R}$.

Prediction 5. SARs change with climate change. In other words, for the same set of species, climate structures at 
different times (and therefore with different shapes of the $\mathbf{E}$ space) will produce different SARs.

Prediction 6. The speed of change in biodiversity indicators will scale with the speed of change in the size of the $\mathbf{E}$ space.

Prediction 7. Since the shape of the SAR is predicted to depend on the location of fundamental niches in $\mathbf{E}$ space relative to the way in which environmental space grows, it is expected that different clades will have different SARs.

\section{Methods}

North America is defined as the part of the Americas north of the border of Panama with Colombia and without the islands. The names of the species of terrestrial mammals in this region were obtained from the database of the International Union for Conservation of Nature Red List, corrected with the help of an expert mammalogist, Rodrigo Medellin, from the National University of Mexico. With this list of names, I queried the Global Biodiversity Information Facility (GBIF) database using the gbif function of the $\mathrm{R}$ package dismo to get 282,949 georeferenced localities for 663 species of terrestrial mammals. The GBIF points for each species were first checked for outliers and erroneous data points (with expert help) and then "thinned" (Aiello-Lammens et al. 2015) to have, for each species, at most one data point per cell in the grid. This reduced the number of records to 69,900 , or about 100 points per species on average.

Using the R package dismo, I created a grid of 5,044 points at $0.83^{\circ}$ resolution, inside the polygon defining North America. The WGS84 datum was used. The resolution was determined only for practical reasons, to obtain a large but manageable number of different grid cells. Using the extract function in the R package dismo, values from the WorldClim database (Hijmans et al. 2005) for annual precipitation in millimeters (BioClim variable $\mathrm{BIO}_{12}$ ) and mean yearly temperature (centigrade times 10 , the $\mathrm{BIO}_{1}$ BioClim variable), at 10 minutes of resolution, were averaged around each centroid point. The GBIF records, with geographic coordinates and BioClim values, have been deposited in the Dryad Digital Repository (https://doi.org/10.5061/dryad.84bq56t; data file: GBIF_Thinned_2; Soberón 2019).

To illustrate the effect of climate change, data sets of temperature and precipitation for the world at present, 20,000 years $\mathrm{BP}$, and 130,000 years BP were used. These are results of general circulation model (GCM) experiments, for the world, at a resolution of $1^{\circ}$ and provided by the Hadley Data Center (Valdes et al. 2017).

To create sequences of regions of growing size, the grid was partitioned by aggregating immediate neighbors using a distance of $1.2^{\circ}$ (to include the eight nearest neighbors of a given point). To do this, six localities in North America were selected as initial regions (in Alaska, in the southern ex- treme of Panama, in the tip of Florida, in the southern tip of Baja California, in the middle of the United States, and in British Columbia; see fig. A1; figs. A1-A6 are available online). In each one of them, five contiguous grid cells were used as the starting region. An extra set of five random localities was also created. A routine written in the package Mathematica then finds contiguous nearest neighbors to create a sequence of increasingly larger regions, formed of contiguous cells, until the 5,044 cells are exhausted. One sequence was created by simply adding random cells (noncontiguous). Each sequence constitutes a "path" of increasing area, but they trace very different routes through environmental space (see fig. 3). The sequences have a maximum of 200 steps needed to use the 5,044 cells, and a minimum of 78 steps.

At every step, the climate density kernel for the subregion was calculated using the SmoothKernelDensity function in the program Mathematica. Kernel densities (Blonder et al. 2014) integrate to 1 . As a measure of the size of the niche volume in the growing regions, I use the normalization denominator of the continuous kernel. In symbols, this is $2 \pi|\mathbf{R}|(\operatorname{det}(\Sigma))^{1 / 2}$, where $|\mathbf{R}|$ is the number of points used to fit the kernel for region $\mathbf{R}$ and $\Sigma$ is the bandwidth matrix for the kernel of region $\mathbf{R}$. This quantity (which, for the variables used, has units of $\left.\left({ }^{\circ} \mathrm{C} \times \mathrm{mm}\right)^{1 / 2}\right)$, is large for flat, spread kernels, and small for climates mostly consisting of a narrow "spike." This conforms to the intuition one may have for the size of a distribution, although its units would change with the dimensions of the niche variables used.

An equal area projection for the grid was not used because the paths of growth of the regions are independent of area. The paths are calculated only by relative proximity of the centroids of cells, and since the PAM is calculated by the climate of points being inside the niches of the species and not spatial cells, area is not a consideration. However, comparing niche volume and geographic area requires a correction for latitude. Correcting equations (Snyder 1987) for the length of a degree of latitude and longitude as a function of latitude (assuming a sphere, for simplicity) are latitude $(\varphi)=\pi r / 180$ and longitude $(\varphi)=\pi r \cos (\varphi) / 180$, with the radius of earth used in the WGS84 ellipsoid $(r=6,378.137 \mathrm{~km})$ and $\varphi$ being the latitude in degrees.

Using the precipitation and temperature variables in the points in GBIF data set, I fitted minimum volume ellipsoids (Van Aelst and Rousseeuw 2009) for those species that had at least five different GBIF points and nonsingular climatic covariance matrices. This left 543 species. The Mathematica code appears in the appendix (available online). ${ }^{1}$ The fitted ellipsoids are regarded as models of the fundamental niche of the species (there are many caveats to this assumption; see "Discussion"). The ellipsoid of the $j$ th

1. Code that appears in The American Naturalist is provided as a convenience to readers. It has not necessarily been tested as part of peer review. 
species is represented by the quadratic form $f q_{j}(v)=$ $\left(v-\mu_{j}\right)^{T} \Sigma_{j}^{-1}\left(v-\mu_{j}\right)$. The level curve defining the fundamental niche is $\left\{\nu \mid f q_{j}(v)=1\right\}$.

Finally, using the different sequences of increasing niche space, PAMs were created by the following procedure. For each one of the 543 species, it was checked whether the climate in the 5,044 cells in the grid was inside or outside the ellipsoid modeling the fundamental niche of the species $\left(f q_{j}(v)<1\right)$. A cell $i, j$ was assigned a value of 1 if the climate in cell $i$ was contained in the fundamental niche of species $j$ and 0 otherwise. This 5,044 $\times 543$ PAM was then subsetted using the different sequences of abutting cells (see the appendix for the code). For every step in the sequence, the following numbers were obtained: (i) the total number of cells in each PAM in the sequence; (ii) the measure of the volume of climatic space; (iii) the total geographic area, corrected by latitude; (iv) the total number of species in the region; (v) the mean number of species per cell; (vi) the mean proportion of environmental space occupied by each species; and (vii) the total number of different species in the region.

It is important to stress that by having a PAM, almost any index of biodiversity pattern (based on incidences) can be constructed (Soberón and Cavner 2015). Total number of species becomes simply one of many aspects of the biodiversity patterns being driven by change in $\mathbf{R}$.

\section{Results}

The first prediction from equation (8) is that as the amount of niche space grows, the mean local number of species $\bar{\alpha}(\mathbf{R})$ should not grow in any specific way, but the proportion of occupied niche space $\bar{\omega}(\mathbf{R})$ (the reciprocal of Whittaker's beta diversity) should decrease. In figure $4 A$ and $4 B$, I show the results for seven different routes of expansion of area (and therefore of niche space). The prediction holds very well, with the exception of the path created by randomly aggregating points (the red lines). It is interesting to stress that the value of $\bar{\alpha}(\mathbf{R})$ remains mostly constant in log-log scale until the end of the interval of growth of $\mathbf{R}$, where it changes to converge to the overall local mean, with a positive or negative slope depending on the path. On the contrary, for $\bar{\omega}(\mathbf{R})$, all of the paths (with the exception of the random one) produce a decreasing relationship with the amount of environmental space. The paths beginning in the northern part of the continent have averages of niche breadth of almost $100 \%$ of the environmental availability. Since the data points are not independent (a consequence of the nested design), no significance values are presented (Drakare et al. 2006), but the linear correlations are all $>0.7$.

The second prediction states that the selected path will determine the actual shape of the SAR, regardless of whether area or niche space volume are used as predictors. In figure 4 , the SARs for the seven different paths used are shown. The SARs are different not only because they begin in different points but also because the slopes at the end are also different. Notice that the amount of niche volume at the beginning of every curve in the top graph is different, since the same area surface in different regions may contain very contrasting amounts of environmental space. For instance, $100 \mathrm{~km}^{2}$ in British Columbia and $100 \mathrm{~km}^{2}$ in Alaska may contain rather contrasting ranges of climatic combinations. Although all of the paths begin with five spatial points of $0.833^{\circ}$, there is a latitudinal effect to the geographic size of a degree, and therefore the minimum value of area in the bottom graph changes. A summary of the regression parameters for figure $4 A$ and $4 B$ appear in table A1 (tables A1, A2 are available online).

I predicted that niche space should be a better predictor of species number than area. However, in North America there is a very good correlation between these two measures of the size of $\mathbf{R}$ and thus no apparent difference between using area or size of niche space to predict species numbers. The main difference between geographic area and environmental space size occurs at the beginning, for small regions situated in contrasting parts of the continent, but all of the paths become very similar at the end. Since the points in the paths are not independent, a conventional statistical analysis to test for equal slopes is not possible, but the results of the regressions appear in table A2.

I expected SARs obtained with contrasting climate structures to have different shapes. This question is complicated because over a period of many thousands of years there have been extinctions and maybe speciation events. I simply used the contemporary list of species, ignoring the Pleistocene megafauna of North America. Three times were used: the present, the glacial maximum 20,000 years ago, and the last interglacial, 130,000 years ago. The three SARs start in Panama (fig. A2) and are different. Most of the difference occurs at the beginning of the SAR. It is important to remember that we are assuming niche conservatism over time.

With regard to changing climatic space, it is known that species change their geographic ranges with climate (Pinsky et al. 2013). What is the amount of change in biodiversity metrics due to climate change (Garcia et al. 2014)? Not surprisingly, this is essentially a function of the position of the niches in climatic space. I illustrate this using some species of the family Leporidae, although other sets of species could have been used. These species were chosen because they illustrate the effect of disjoint versus nested niches. The question is, What is the time derivative of the mean breadth of the existing niches of a group of species? Because of equation (8), this affects the total number of species living in a region. I used the present and the output of a present GCM (see "Methods") as well as two groups of species, one (fig. $5 \mathrm{~A}$ ) with a set of fundamental niches with very little overlap and another (fig. 5B) with large overlap. 

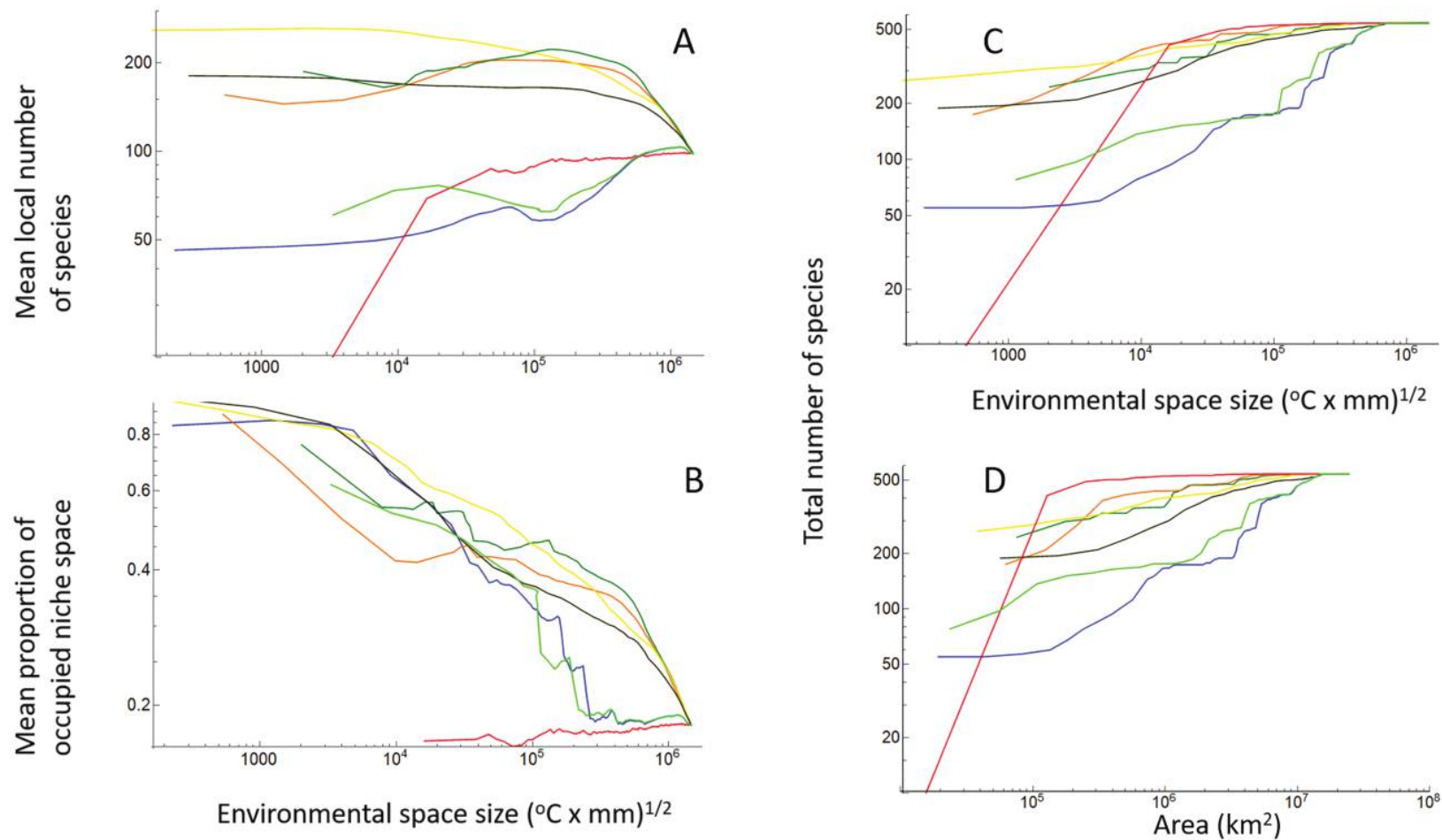

Figure 4: Log-log graphs of $(A)$ the mean number of species $\bar{\alpha}(\mathbf{R})$ and $(B)$ the mean occupied niche space $\bar{\omega}(\mathbf{R})$, both as a function of environmental niche space size. The species-area relationship is shown as a function of niche space in panel $C$ and as a function of area in panel $D$. The regions grow in area beginning in six contrasting geographic points (see text). Starting regions are as follows: yellow, southern tip of Florida; bright green, British Columbia; dark green, Panama; orange, southern tip of Baja California; brown, Central Plains; blue, Alaska; and red, random.

The time derivative of niche size for species $j$ is obtained from equation (3):

$$
\begin{aligned}
\frac{\mathrm{d} \omega_{j}(t)}{\mathrm{d} t} & =\frac{\mathrm{d}}{\mathrm{d} t} \int_{F_{j}} \mathbf{E}_{\mathrm{R}}(\boldsymbol{\nu} ; t) \mathrm{d} \boldsymbol{\nu} \\
& =\int_{F_{j}} \frac{\mathrm{d}}{\mathrm{d} t} \mathbf{E}_{\mathbf{R}}(\boldsymbol{\nu} ; t) \mathrm{d} \boldsymbol{\nu} .
\end{aligned}
$$

And its average, over any group of species, would be

$$
\frac{\mathrm{d}}{\mathrm{d} t} \bar{\omega}(t)=\frac{1}{S} \sum_{j=1}^{S} \frac{\mathrm{d}}{\mathrm{d} t} \omega_{j}(t)
$$

But the last term in equation (12) is approximately

$$
\begin{aligned}
\int_{F_{j}} \frac{\mathrm{d}}{\mathrm{d} t} \mathbf{E}_{\mathrm{R}}(\nu ; t) \approx & \frac{1}{\Delta t} \int_{F_{j}}\left[\mathbf{E}_{\mathbf{R}}(\boldsymbol{\nu} ; t)-\mathbf{E}_{\mathbf{R}}(\boldsymbol{\nu} ; t+\Delta t)\right] \mathrm{d} \boldsymbol{\nu} \\
= & \frac{1}{\Delta t} \int_{F_{j}} \mathbf{E}_{\mathbf{R}}(\boldsymbol{\nu} ; t) \mathrm{d} \boldsymbol{\nu} \\
& -\frac{1}{\Delta t} \int_{F_{j}} \mathbf{E}_{\mathbf{R}}(\boldsymbol{\nu} ; t+\Delta t) \mathrm{d} \boldsymbol{\nu} .
\end{aligned}
$$

And if the integral would be taken over the entire domain, this value would be zero, since both probability density kernels in equation (14) are normalized and integrate to 1. The measure of the nonnormalized kernels at time $t$ and $t+$ $\Delta t$ (over the entire domain) are $\left|\mathbf{E}_{\mathbf{R}}(t)\right|$ and $\left|\mathbf{E}_{\mathbf{R}}(t+\Delta t)\right|$, respectively, and therefore the integral, over the whole domain, of the time derivative of the nonnormalized kernels is simply

$$
\frac{\mathrm{d}}{\mathrm{d} t}\left|\mathbf{E}_{\mathbf{R}}(t)\right|
$$

This means that for a group of species like that depicted in figure $5 \mathrm{~A}$, the rate of change of the mean size of the existing niches is approximately equal to the rate of change of climate volume for the entire region. Because of the equality in equation (10), this implies that the mean proportional alpha diversity is changing at the same speed as climate in the region. However, for a group of species like the one illustrated in figure $5 B$, with high covariance in the position and substantial overlap of the fundamental niches, the rate of change of local diversity needs to be calculated from the specifics of the location and size of their niches. The bottom line is that no general statements about the size and/or direction of change 


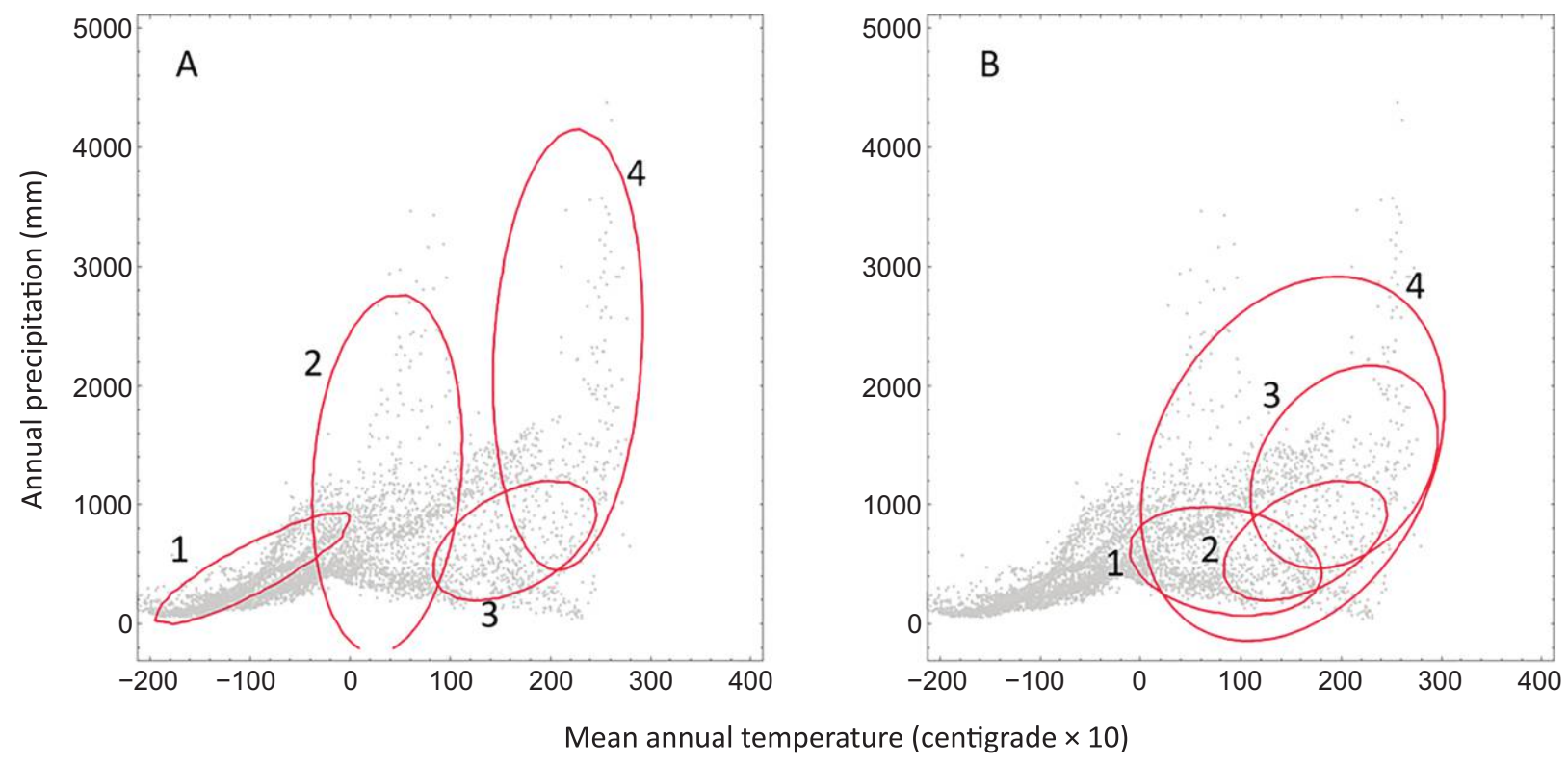

Figure 5: Fundamental niches of a contrasting set of species. In panel $A$, species with very little niche overlap (1, Lepus arcticus; 2, Ochotona princeps; 3, Lepus callotis; 4, Sylvilagus brasiliensis) are shown. In panel B, species with large overlap (1, Lepus townsendii; 2, L. callotis; 3, Sylvilagus cunicularius; 4, Sylvilagus floridanus) are shown. Climate points are at present.

can be made using information only on the size of the region; the information about the position of $\mathbf{F}$ in $\mathbf{E}$ is of crucial importance.

Finally, the last prediction was that different clades would have different SARs. In some sense this should be obviously true, since different clades have different numbers of species. However, it has been shown that the relationship between climate and species richness changes for different clades (Buckley et al. 2010), and this is to be expected assuming that different clades cluster differently in environmental space (as illustrated in fig. 5). The question of the relationship between phylogeny and position of fundamental niches is a deep one (Donoghue 2008; Buckley et al. 2010), and there is no space to explore it here. However, in the appendix I include data showing how six orders of mammals of North America (i) have different positions in niche space and (ii) occupy different amounts of niche space. Therefore, their SARs are also different.

\section{Discussion}

Most of the theoretical work about SARs is built around either (i) the statistical distributions of abundance of individuals among species (Preston 1962; May 1975), (ii) the spatial pattern of randomly placed individuals (Coleman 1981; He and Legendre 2002), or (iii) the spatial pattern of entire ranges (Ney-Nifle and Mangel 1999; Allen and White
2003). The main point of the present article is that an entire new framework for studying biodiversity patterns in general (at large spatial scales) - and specifically the SAR - can be built on considerations about the interactions between a suitably defined niche space and the placing of Grinnellian niches in that space. This is an approach that has seldom been tried in the past and that shows that different paths of increasing area produce different patterns of environmental volume growth, and thus different SARs; that it is the equivalent of Whittaker's beta diversity in niche space what drives most of the SAR; that there is a ceiling to the SARs; and that how fast this is reached depends on the pattern of location of $\mathbf{F}$ in E. Finally, it also predicts that SARs in different epochs will be different and allows calculation of the rate of change of mean local diversity. For clades that cover most of niche space, this rate of change equals the rate of change of the volume of environmental space.

Much theory about Grinnellian niches has been accumulating in recent years ( Jackson and Overpeck 2000; Williams and Jackson 2007; Hirzel and Le Lay 2008; Godsoe 2009; Peterson et al. 2011; Broennimann et al. 2012; Petitpierre et al. 2012; Drake 2015; Soberón and Arroyo-Peña 2017). In the field of environmental niche modeling, realized niches can be defined operationally and calculated on the basis of gigabytes of available data (Peterson et al. 2011). However, the approach I present here depends on estimating fundamental niches. Estimation of multivariate fundamental niches is a notoriously difficult problem since, strictly speaking, it 
requires experimental work (Kearney 2006; Soberón and Arroyo-Peña 2017), which is very seldom performed (Sunday et al. 2011). To obtain an approximation to the fundamental niches, I assume (i) that fundamental niches have a convex shape, like ellipsoids (Maguire 1973; Brown 1995; Soberón and Nakamura 2009; Drake 2015); (ii) that the fundamental niche should contain the realized niche (Hutchinson 1957; Soberón and Arroyo-Peña 2017); and (iii) that the observation points are instances of the realized niche (Peterson et al. 2011). Therefore, ellipsoids in $n$ variables containing wellestablished observations may be regarded as some lower limit to the projection in $n$-variable space of the hypothetical true fundamental niche of a species. Although the above is a strong assumption, experimental data are available mostly for one dimension (Bennett et al. 2018). For more than one variable and for most species, we simply do not have data on the fundamental niches.

Assuming that an $\mathbf{F}$ set can be estimated, knowledge of this, together with the assumptions of the NMB, allows actually calculating many quantities of biogeographic interest, as it is shown in this work. The number of species is shown to depend fundamentally on the mean proportion of occupied niche space, which is the reciprocal of Whittaker's beta diversity. This in turn depends on the location of the fundamental niches. A fundamental question therefore is, What determines the position of $\mathbf{F}$ in niche space? When we have a theory of that, we shall have a theory of biodiversity patterns at biogeographical scales, a theory that probably will be historical, not ecological (Wiens and Donoghue 2004; Buckley et al. 2010). What kind of climate space a species originated in and how conserved are fundamental niches are the key questions.

Although the estimation of $\mathbf{F}$, on the one hand, and the validity (or not) of the assumptions of the NMB, on the other, are still problems requiring much work, stating the problems of the structure and dynamics of biodiversity explicitly in terms of causal climatic, geographic, and historic factors is of great value (Fine 2015). It stresses the importance of answering questions that ecologists have, with some exceptions (Wiens and Donoghue 2004; Buckley et al. 2010; Carstensen et al. 2013), basically marginalized in the past, such as those related to the shapes of fundamental niches; their measure, position, and covariance in environmental space; their evolutionary histories; and the dynamics of change of favorable conditions in environmental spaces. Finally, this approach places realistic climate and geography firmly in the center of a computational theory of the dynamics of biodiversitycomputational in the sense that, as this article shows, one can use large databases to calculate niches, their volumes, their positions, and, using mechanistic assumptions (the NMB), predict distributions. This allows using the NMB to create the niche-based PAM and, consequently, a niche-driven view of many biodiversity patterns, including the SAR, based on equation (8). The emphasis is on using available data to calculate quantities of theoretical and practical importance. Given the recent accumulation of theory about Grinnellian niches, applying it to classic questions should be a fruitful avenue of research. Specifically, relaxing the assumptions of the NMB should be explored. The simplest to relax is the assumption of no dispersal limitation. This can be relaxed using alreadyavailable techniques, and doing it has a wealth of potentialities (Garcia et al. 2014).

The main differences between a classic and a Grinnellian niche approach to study SARs are that the latter requires knowledge of the individual niches of the species and that the direct driver of change is the structure of climate in a given realistic region. The approach is entirely data driven. On the contrary, conventional approaches characterize the SAR using two parameters (maybe three) to attempt to capture the ecology and history of a set of species and one physical measurement, area, as a proxy for more direct drivers. Sometimes a covariate of area is used, such as habitat diversity (Ricklefs and Lovette 1999). In classic approaches one seldom starts with an empirical set of spatial distributions of individuals or empirical polygons of the areas of distribution of species in the pool, although a recent exception would be Storch et al. (2012). In most classic approaches, mathematically convenient assumptions are made about the distribution of abundances or the placement of individuals or distributional ranges in space. The theories used to predict SARs by placing random areas in space (Allen and White 2003) or by solving master equations of neutral theories (O'Dwyer and Green 2010) predict a growing curve, with no right-side limit. This is probably a consequence of implicitly assuming a world of infinite size, such as when the sampling area increases, it will keep encountering new areas (or fundamental niches) at a constant rate. Implicitly assuming very large or infinite number of species may be mathematically convenient, but it is empirically untenable. Examples of ever-increasing functions at the large-size part of the SAR may all be either cases of not getting enough samples toward the right-side limit, like fig. 21.15 in Rosenzweig (1995), or cases of never getting close to it (Storch et al. 2012), because in real life the number of species is finite and often on the order of just hundreds or thousands of species, and the area is also finite. Therefore, any realistic SAR will eventually reach a limit in both axes (Williamson et al. 2001; He and Legendre 2002). Whether this point is reached with a slope near zero or rather a very positive slope depends on the path. This is exactly what figure 4 shows, and it is a widely observed pattern (Storch et al. 2003).

I would like to end on a semiphilosophical note. Ecology has entered the era of large data sets (Hampton et al. 2013). Some questions that used to require theoretical predictions derived from analytically tractable assumptions now require looking in databases. This is increasingly the case of areas of 
distributions and of Grinnellian niches. With wide availability of data, the role of theory in ecology and in biogeography is changing. Rather than analyzing analytically tractable models, perhaps we need to develop the logical structures and assumptions necessary to organize and postulate relationships among the concepts sustained by such databases and perform actual calculations on the data rather than statistical inferences. I hope I have shown that this approach is feasible and interesting.

\section{Acknowledgments}

This work is the result of years of collaboration and debate with colleagues, especially A. T. Peterson, E. Martínez-Meyer, A. Christen, H. Arita, P. Rodríguez, and C. Martínez del Río, and with students or former students, including A. LiraNoriega, L. Osorio-Olvera, L. Jimenez, and participants of the niche-modeling seminar at the University of Kansas. R. Medellin helped me deal with the taxonomy of the mammals. I am grateful to L. Buckley and an anonymous reviewer for their creative and positive suggestions. My wife, Tita, was extremely patient with my writing-related eccentricities, and Blitzi Soberón provided moral encouragement. I was partially supported by a National Science Foundation grant (ABI 1458640).

\section{Literature Cited}

Aiello-Lammens, M. E., R. A. Boria, A. Radosavljevic, B. Vilela, and R. P. Anderson. 2015. spThin: an R package for spatial thinning of species occurrence records for use in ecological niche models. Ecography 38:541-545.

Allen, A. P., and E. P. White. 2003. Effects of range size on speciesarea relationships. Evolutionary Ecology Research 5:493-499.

Arita, H. T., J. A. Christen, P. Rodriguez, and J. Soberón. 2008. Species diversity and distribution in presence-absence matrices: mathematical relationships and biological implications. American Naturalist 172:519-532.

Arrhenius, O. 1921. Species and area. Journal of Ecology 9:95.

Aspinall, R., and B. G. Lees. 1994. Sampling and analysis of spatial environmental data. Pages 1066-1097 in T. C. Waugh and R. G. Healey, eds. Proceedings of the Sixth International Symposium on Spatial Data Handling. University of Edinburgh, Edinburgh.

Begon, M., C. R. Townsend, and J. L. Harper. 2006. Ecology: from individuals to ecosystems. Blackwell, Oxford.

Bennett, J. M., P. Calosi, S. Clusella-Trullas, B. Martínez, J. Sunday, A. C. Algar, M. B. Araújo, et al. 2018. GlobTherm, a global database on thermal tolerances for aquatic and terrestrial organisms. Scientific Data 5:180022.

Blonder, B., C. Lamanna, C. Violle, and B. J. Enquist. 2014. The $n$-dimensional hypervolume. Global Ecology and Biogeography 23:595-609.

Broennimann, O., M. C. Fitzpatrick, P. B. Pearman, B. Petitpierre, L. Pellissier, N. G. Yoccoz, W. Thuiller, et al. 2012. Measuring ecological niche overlap from occurrence and spatial environmental data. Global Ecology and Biogeography 21:481-497.
Brown, J. H. 1995. Macroecology. University of Chicago Press, Chicago. Buckley, L. B., T. J. Davies, D. D. Ackerly, N. J. Kraft, S. P. Harrison, B. L. Anacker, H. V. Cornell, et al. 2010. Phylogeny, niche conservatism and the latitudinal diversity gradient in mammals. Proceedings of the Royal Society B 277:rspb20100179.

Calabrese, J. M., G. Certain, C. Kraan, and C. F. Dormann. 2014. Stacking species distribution models and adjusting bias by linking them to macroecological models. Global Ecology and Biogeography 23:99-112.

Carstensen, D. W., J. P. Lessard, B. G. Holt, M. Krabbe Borregaard, and C. Rahbek. 2013. Introducing the biogeographic species pool. Ecography 36:1310-1318.

Chase, J. M., and M. Leibold. 2003. Ecological niches: linking classical and contemporary approaches. University of Chicago Press, Chicago.

Cohen, J. E. 1978. Food webs and niche space. Princeton University Press, Princeton, NJ.

Coleman, B. D. 1981. On random placement and species-areas relations. Mathematical Biosciences 54:191-215.

Colwell, R. K., and T. F. Rangel. 2009. Hutchinson's duality: the once and future niche. Proceedings of the National Academy of Sciences of the USA 106:19644-19650.

Cooper, J. C., and J. Soberón. 2018. Creating individual accessible area hypotheses improves stacked species distribution model performance. Global Ecology and Biogeography 27:156-165.

Donoghue, M. J. 2008. A phylogenetic perspective on the distribution of plant diversity. Proceedings of the National Academy of Sciences of the USA 105:11549-11555.

Drakare, S., J. J. Lennon, and H. Hillebrand. 2006. The imprint of the geographical, evolutionary and ecological context on species-area relationships. Ecology Letters 9:215-227.

Drake, J. M. 2015. Range bagging: a new method for ecological niche modelling from presence-only data. Interface 12:20150086.

Fine, P. V. 2015. Ecological and evolutionary drivers of geographic variation in species diversity. Annual Review of Ecology, Evolution, and Systematics 46:369-392.

Garcia, R. A., M. Cabeza, C. Rahbek, and M. B. Araújo. 2014. Multiple dimensions of climate change and their implications for biodiversity. Science 344:1247579.

Gleason, H. A. 1922. On the relation between species and area. Ecology 3:158-162.

Godsoe, W. 2009. I can't define the niche but I know it when I see it: a formal link between statistical theory and the ecological niche. Oikos 119:53-60.

Gutiérrez, E. E., R. A. Boria, and R. P. Anderson. 2014. Can biotic interactions cause allopatry? niche models, competition, and distributions of South American mouse opossums. Ecography 37:741-753.

Hampton, S. E., C. A. Strasser, J. J. Tewksbury, W. K. Gram, A. E. Budden, A. L. Batcheller, C. S. Duke, et al. 2013. Big data and the future of ecology. Frontiers in Ecology and the Environment 11:156-162.

Harte, J. 2011. Maximum entropy and ecology: a theory of abundance, distribution, and energetics. Oxford University Press, Oxford.

He, F., and P. Legendre. 2002. Species diversity patterns derived from species-area models. Ecology 83:1185-1198.

Hijmans, R. J., S. Cameron, J. Parra, P. G. Jones, and A. Jarvis. 2005. Very high resolution interpolated climate surfaces for global land areas. International Journal of Climatology 25:1965-1978.

Hirzel, A. H., and G. Le Lay. 2008. Habitat suitability modelling and niche theory. Journal of Applied Ecology 45:1372-1381.

Holt, R. D. 2009. Bringing the Hutchinsonian niche into the 21 st century: ecological and evolutionary perspectives. Proceedings of the National Academy of Sciences of the USA 106:19659-19665. 
Holt, R. D., and R. Gomulkiewicz. 1997. The evolution of species niches: a populations dynamic perspective. Pages $25-50$ in $\mathrm{H}$. G. Othmer, F. R. Adler, M. A. Lewis, and J. Dillon, eds. Case studies in mathematical modelling: ecology, physiology and cell biology. Prentice-Hall, Englewood Cliffs, NJ.

Hutchinson, G. E. 1957. Concluding remarks. Cold Spring Harbor Symposia on Ouantitative Biology 22:415-427.

1978. An introduction to population ecology. Yale University Press, New Haven, CT.

Jackson, S. T., and J. T. Overpeck. 2000. Responses of plant populations and communities to environmental changes of the late Quaternary. Paleobiology 26(suppl.):194-220.

Kearney, M. 2006. Habitat, environment and niche: what are we modelling? Oikos 115:186-191.

Leathwick, J. 1998. Are New Zealand's Nothofagus species in equilibrium with their environment? Journal of Vegetation Science 9:719-732.

Leitner, W. A., and M. L. Rosenzweig. 2003. Nested species-area curves and stochastic sampling: a new theory. Oikos 79:503-512.

Lomolino, M. V. 2000. Ecology's most general, yet protean pattern: the species-area relationship. Journal of Biogeography 27:17-26.

MacArthur, R. 1972. Geographical ecology. Harper \& Row, New York.

Maguire, B. 1973. Niche response structure and the analytical potentials of its relationship to the habitat. American Naturalist 107:213-246.

May, R. M. 1975. Patterns of species abundance and diversity. Pages 81120 in M. L. Cody and J. M. Diamond, eds. Ecology and evolution of communities. Belknap, Cambridge, MA.

Meyer, A. L., and M. R. Pie. 2018. Environmental prevalence and the distribution of species richness across climatic niche space. Iournal of Biogeography 45:2348-2360.

Moshtagh, N. 2005. Minimum volume enclosing ellipsoid. Convex Optimization 111:112

Ney-Nifle, M., and M. Mangel. 1999. Species-area curves based on geographic range and occupancy. Journal of Theoretical Biology 196:327-342.

Nogués-Bravo, D., and M. B. Araújo. 2006. Species richness, area and climate correlates. Global Ecology and Biogeography 15:452-460.

O’Dwyer, J. P., and J. L. Green. 2010. Field theory for biogeography: a spatially explicit model for predicting patterns of biodiversity. Ecology Letters 13:87-95.

Owens, H. L., L. P. Campbell, L. L. Dornak, E. E. Saupe, N. Barve, J. Soberón, K. Ingenloff, et al. 2013. Constraints on interpretation of ecological niche models by limited environmental ranges on calibration areas. Ecological Modelling 263:10-18.

Peterson, A. T. 2011. Ecological niche conservatism: a time-structured review of evidence. Journal of Biogeography 38:817-827.

Peterson, A. T., J. Soberón, R. G. Pearson, R. Anderson, E. MartínezMeyer, M. Nakamura, and M. Araújo. 2011. Ecological niches and geographic distributions. Princeton University Press, Princeton, NJ.

Petitpierre, B., C. Kueffer, O. Broennimann, C. Randin, C. Daehler, and A. Guisan. 2012. Climatic niche shifts are rare among terrestrial plant invaders. Science 335:1344-1348.

Pinsky, M. L., B. Worm, M. J. Fogarty, J. L. Sarmiento, and S. A. Levin 2013. Marine taxa track local climate velocities. Science 341:12391242.

Preston, F. W. 1962. The canonical distribution of commonness and rarity. I, II. Ecology 43:185-215, 410-432.

Qiao, H., E. E. Saupe, J. Soberón, A. T. Peterson, C. E. Myers, D. C. Collar, and J. L. Bronstein. 2016. Impacts of niche breadth and dispersal ability on macroevolutionary patterns. American Naturalist 188:149-162.
Rangel, T. F., J. A. Diniz-Filho, and R. K. Colwell. 2007. Species richness and evolutionary niche dynamics: a spatial pattern-oriented simulation experiment. American Naturalist 170:602-616.

Ricklefs, R. E., and I. J. Lovette. 1999. The roles of island area per se and habitat diversity in the species-area relationships of four Lesser Antillean faunal groups. Journal of Animal Ecology 68:1142-1160.

Rosenzweig, M. L. 1995. Species diversity in space and time. Cambridge University Press, Cambridge.

Routledge, R. D. 1977. On Whittaker's components of diversity. Ecology 58:1120-1127.

Scheiner, S. M., A. Chiarucci, G. A. Fox, M. R. Helmus, D. J. McGlinn, and M. R. Willig. 2011. The underpinnings of the relationship of species richness with space and time. Ecological Monographs 81:195213.

Schluter, D., and R. E. Ricklefs. 1993. Species diversity: an introduction to the problem. Pages 1-12 in R. E. Ricklefs and D. Schluter, eds. Species diversity in ecological communities: historical and geographical perspectives. University of Chicago Press, Chicago.

Shmida, A., and M. V. Wilson. 1985. Biological determinants of species diversity. Journal of Biogeography 12:1-20.

Snyder, J. P. 1987. Map projections - a working manual. US Geological Survey Professional Papers. US Geological Survey, Washington, DC.

Soberón, J. 2007. Grinnellian and Eltonian niches and geographic distributions of species. Ecology Letters 10:1115-1123.

. 2010. Niche and area of distribution modeling: a population ecology perspective. Ecography 33:159-167.

- 2019. Data from: A Grinnellian niche perspective on speciesarea relationships. American Naturalist, Dryad Digital Repository, https://doi.org/10.5061/dryad.84bq56t.

Soberón, J., and B. Arroyo-Peña. 2017. Are fundamental niches larger than the realized? testing a 50 -year-old prediction by Hutchinson. PLoS ONE 12:e175138.

Soberón, J., and J. Cavner. 2015. Indices of biodiversity pattern based on presence-absence matrices: a GIS implementation. $\underline{\text { Biodiversity }}$ Informatics 10:22-34.

Soberón, J., and G. Ceballos. 2011. Species richness and range size of the terrestrial mammals of the world: biological signal within mathematical constraints. PLoS ONE 6:e19359.

Soberón, J., and M. Nakamura. 2009. Niches and distributional areas: concepts, methods, and assumptions. Proceedings of the National Academv of Sciences of the USA 106:19644-19650.

Soberón, J., and A. T. Peterson. 2005. Interpretation of models of fundamental ecological niches and species' distributional areas. Biodiversity Informatics 2:1-10.

Storch, D., P. Keil, and W. Jetz. 2012. Universal species-area and endemics-area relationships at continental scales. Nature 488:78-81.

Storch, D., A. Sizling, and K. Gaston. 2003. Geometry of the speciesarea relationship in central European birds: testing the mechanism. Journal of Animal Ecology 72:509-519.

Sunday, J. M., A. E. Bates, and N. K. Dulvy. 2011. Global analysis of thermal tolerance and latitude in ectotherms. Proceedings of the Roval Societv B 278:1823-1830.

Svenning, J.-C., and F. Skov. 2004. Limited filling of the potential range in European tree species. Ecology Letters 7:565-573.

Tjørve, E. 2003. Shapes and functions of species-area curves: a review of possible models. Journal of Biogeography 30:827-835.

Triantis, K., M. Mylonas, K. Lika, and K. Vardinoyannis. 2003. A model for the species-area-habitat relationship. Journal of Biogeography 30:19-27. 
Ulrich, W., W. Kryszewski, P. Sewerniak, R. Puchałka, G. Strona, and N. J. Gotelli. 2017. A comprehensive framework for the study of species co-occurrences, nestedness and turnover. Oikos 126:1607-1616. Valdes, P. J., E. Armstrong, M. P. Badger, C. D. Bradshaw, F. Bragg, T. Davies-Barnard, J. J. Day, et al. 2017. The BRIDGE HadCM3 family of climate models: HadCM3@ Bristol v1.0. Geoscientific Model Development 10:3715-3743.

Van Aelst, S., and P. Rousseeuw. 2009. Minimum volume ellipsoid. Wiley Interdisciplinary Reviews: Computational Statistics 1:71-82.

Vilela, B., and F. Villalobos. 2015. letsR: a new R package for data handling and analysis in macroecology. Methods in Ecology and Evolution 6:1229-1234.

Whittaker, R. H. 1960. Vegetation of the Siskiyou Mountains, Oregon and California. Ecological Monographs 30:279-338.
Wiens, J., and M. Donoghue. 2004. Historical biogeography, ecology and species richness. Trends in Ecology and Evolution 19:639644.

Williams, C. B. 1964. Patterns in the balance of nature and related problems of quantitative ecology. Academic Press, New York.

Williams, J. W., and S. T. Jackson. 2007. Novel climates, no-analog communities, and ecological surprises. Frontiers in Ecology and the Environment 5:475-482.

Williamson, M., K. J. Gaston, and W. M. Lonsdale. 2001. The speciesarea relationship does not have an asymptote! Journal of Biogeography $28: 827-830$

Associate Editor: Lauren B. Buckley Editor: Alice A. Winn

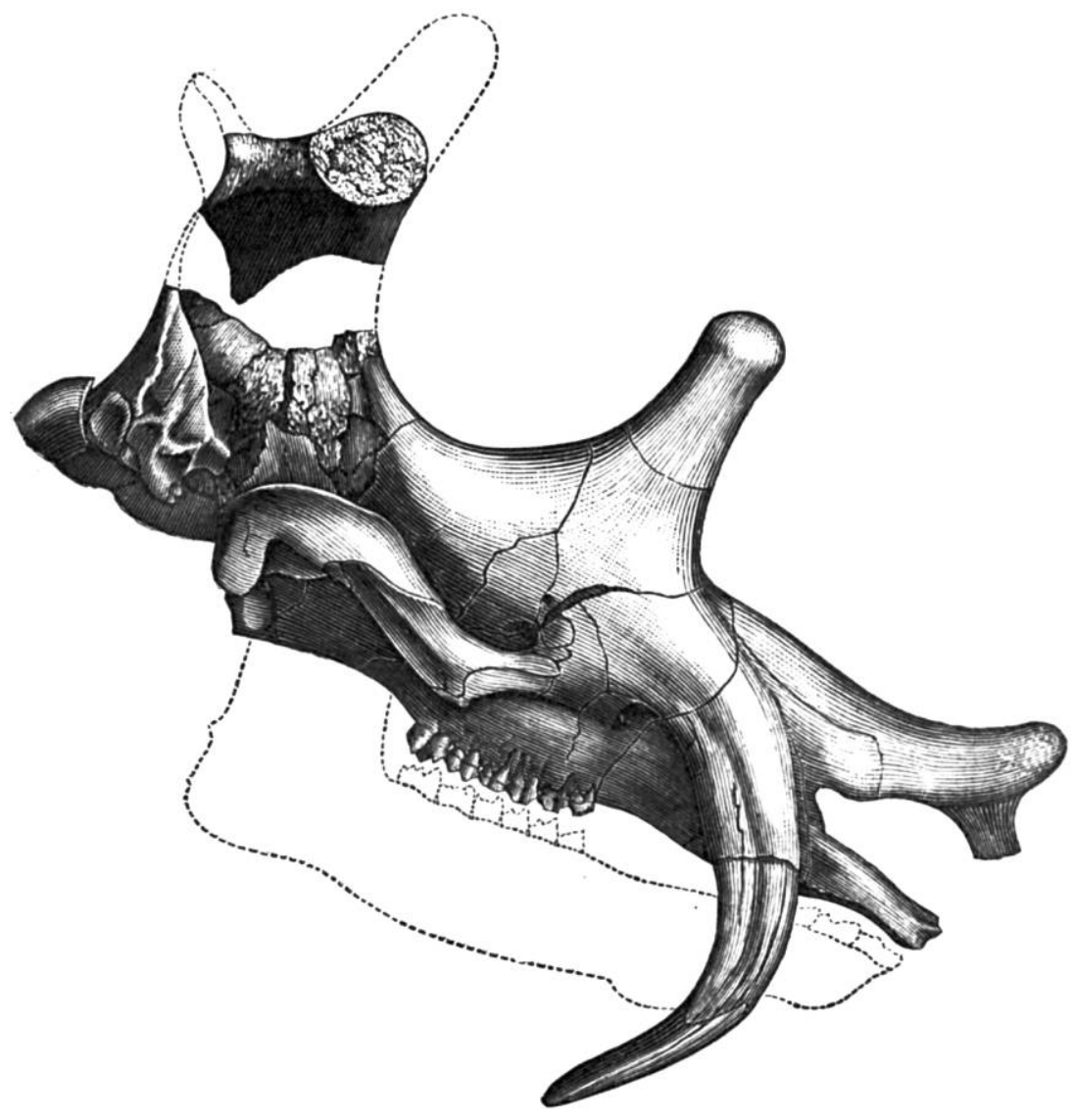

"A third species of Loxolophodon is described under the name of L. speirianum, which, judging from the figures given, was not less extraordinary than the other species of the genus." Figured: "Loxolophodon cornutus Cope." From the review of A Memoir on the Loxolophodon and Uintatherium (The American Naturalist, 1881, 15:888-889). 